\title{
Four-Hand Piano Transcriptions and the Reception of Symphonic Repertoire in Nineteenth-Century Europe
}

\author{
Elissa Miller-Kay \\ Princess Galyani Vadhana Institute of Music \\ 2010 Arun Amarin Soi 36, Bang Yi Khan, Bang Phlat \\ Bangkok, Thailand 10700 \\ email: elissa.m@pgvim.ac.th
}

Published online: 28 December 2018

Cite this article (APA): Miller-Kay, E. (2018). Four-Hand Piano Transcriptions and the Reception of Symphonic Repertoire in Nineteenth-Century Europe. Malaysian Journal of Music, 7, 195-207.

\begin{abstract}
In the nineteenth century, listening to a symphony was a rare and precious treat. Few could afford to attend the symphony regularly, and even those who could would be lucky to hear a favourite work once every few years. There was, however, one way for nineteenth-century music lovers to hear their favourite symphonies anytime on demand: by playing arrangements. Arrangements of symphonies, particularly those for piano four-hands, were phenomenally popular. Amateur musicians would play through arrangements before a concert to familiarise themselves with unknown works and after to re-experience the music they enjoyed. In the twentieth century, recordings took over this function. Today, it is not the sonic magnificence of the orchestra that is rare and precious; it is the act of music-making. This paper examines the roles that four-hand piano transcriptions played in the reception of symphonic repertoire during the nineteenth century and, by way of conclusion, suggests some pedagogical applications of the findings. The history of four-hand piano transcriptions demonstrates the crucial role that active participation in music-making plays in the understanding and enjoyment of symphonic repertoire.
\end{abstract}

Keywords: arrangements, four hand, nineteenth century, piano, reception, transcriptions

\section{Introduction}

Until relatively recently, most people who attended classical music concerts also played instruments themselves. In fact, audiences were often referred to as 'amateurs' a word that connotes an ability to play as well as an enjoyment of 
listening. Naturally, many amateurs wanted to play the same music at home that they enjoyed hearing in the concert hall. This resulted in a veritable craze for arrangements - particularly for the piano. As Temperley (1959) observed of the London concert scene,

Every work, whether a symphony, an opera, an oratorio, or a song, that gained popularity in public performance, was promptly arranged for the pianoforte solo or duet, and sold in large quantities to the thousands of amateurs who wished to revive in their own homes the pleasures they had experienced in the concert-room. (p. 35)

The situation was similar in other European cities. As reported in the Leipzig Allgemeine musikalische Zeitung (1863), four-hand arrangements had

gained such extraordinary popularity, that despite the many more or less practical arrangements of all significant old and new works written for instruments or voice, eager four-hand performers who are accustomed to working through a halfdozen symphonies, quartets, or the like in an afternoon or evening can scarcely be supplied with enough new material. (cited in Christensen, 1999, p. 258)

Arrangements allowed people living outside of major cities to experience repertoire they may otherwise never get a chance to hear. In 1822, a reviewer for the Quarterly Musical Magazine and Review opined,

the passion for arrangements is, we think, a little run mad.- It however has its benefits: it extends very widely the knowledge of the greatest composers, for there are many persons, in the provinces especially, who have few other chances of becoming acquainted with their works. (Vol. 4, p. 229)

Even in major cities, amateurs often had to wait years to hear a given symphony. During the decade from 1880-1890, for example, a Viennese Beethoven enthusiast had to wait almost a decade to hear each of his symphonies performed once by a professional orchestra (Botstein, 2009, p. 7). Composers thus recognised that arrangements were the primary form in which their music would be disseminated. Brahms, a frequent arranger of his own music, indicated in a letter to his publisher just how important four-hand arrangements were, "I have devoted myself to a noble occupation: arranging my immortal [Requiem] so that it can also be enjoyed by four-handed souls. Now it cannot perish" (Van Camp \& Ottley, 2002, p. 59). Beethoven arranged his seventh symphony for piano himself, and authorised other composers such as Moscheles and Clementi to make arrangements of many other works. At the same time, he expressed annoyance at the numerous shoddy, unauthorised arrangements of his compositions being made. 'Arrangement', he complained, "is a thing against which now-a-days (in times so fruitful- of arrangements) a composer has to strive in vain" (Grove, 1962, p. 16).

Arrangements allowed-or to look at it another way, required-music lovers to actively engage in the music-making process. Most arrangements required more than one player and thus playing them was an inherently social activity. For 
these reasons, arrangements facilitated both deep musical contemplation and social engagement.

\section{The Family Orchestra}

While arrangements were made for various instrument combinations throughout the nineteenth-century, it was the four-hand piano transcription that reigned supreme. Why was this genre in particular so popular? One reason undoubtedly was the widespread popularity of the piano itself. Over the course of the century, piano sales soared throughout Europe and North America. In the United Kingdom, for example, Broadwood, one of the premiere manufacturers, sold approximately 1000 pianos in 1810, up from about 250 per year in the early 1790s (Taylor, 2010, p. 127). In 1850 , approximately 23,000 pianos were made in the United Kingdom and, by 1910, the number had increased to 75,000 (Ehrlich, 1990, p. 222).

Pianos were made in a remarkable variety of shapes and sizes: from small cottage uprights to squares, to concert grands. As befitting the capitalist spirit of the times, there was a piano for almost any income level. The piano was a standard fixture in middle and upper-class homes, and the ability to play was an expected accomplishment for any young women of standing.

All these piano owners and players were constantly in search of new music to play. Publishers released a vast and diverse array of repertoire: small parlour pieces, arrangements of popular tunes, serious concert works, virtuosic showpiece, and all manner of chamber music. Piano duets were particularly popular. Adolph Hofmeister's catalogue of published music for 1845 contains 49 pages listing fourhand repertoire. To compare, the listing for music for piano and violin runs about half as long, 24 pages (Hofmeister, 1845).

The piano was particularly well suited to the task of realising an orchestral score. Unlike other domestic instruments such as the violin, guitar and flute, the piano could approach the sound of a large ensemble. As the nineteenth-century progressed, this ability only improved. In 1800, most pianos had a range of five octaves. By the 1860s, seven octaves were standard - a more comfortable size for four hands to fit along. The introduction of cast iron frames in the mid-century allowed for the piano strings to be held under greater tension, thus increasing the resonance. The damper control was moved from a knee lever to a foot pedal where it could be used frequently with ease. The principal motive underlying all of these changes was a desire to make the instrument more orchestral. Playing styles evolved hand in hand with these technological developments. The following passage from Fétis and Moscheles' piano method (cited in Rowland, 1993) contrasts Liszt's playing in the 1830s with that of Hummel, a pianist of the previous generation,

[Liszt's] school is the most complete deviation from that of Hummel that can well be imagined. Delicacy of touch is by no means the chief object of this master, whose ideas are directed to increasing the powers of the piano, and to the necessity of making it, as much as possible, resemble the effects of an orchestra. Hence those peculiar combinations produced by the frequent employment of the pedals, united to various peculiar modes of striking the keys. (p. 107) 
Of course, both the playing abilities and the instrumental capacities in an average domestic setting would not be comparable to that of a Liszt concert. Still, the aesthetic shift suggests there was a new ideal to aim for. And, with two players instead of one, amateurs might hope to occasionally reach Lisztian volumes, if nothing else. In 1877, John Hullah, a well-known British music teacher, tellingly referred to the piano as the 'family orchestra' (Hullah, 1877). This points to the centrality of orchestral transcriptions to the piano's domestic function.

\section{Intimacy and Grandeur}

Piano duets are the most intimate form of chamber music. They are the only genre within the classical tradition where two players share a single instrument. When playing a four-hand duet, two players sit side by side, one playing the higher register and the other the lower. The two players must merge their sound in a way that is required in no other setting. Instead of dialog and contrast, we have two players matching their sound and playing as one. As Edward Cone (1974) colourfully described it, the players become a single 'four-handed monster' (p. 135).

Consider, for example, the following passage from Beethoven's 'Archduke' Trio Op. 97 (Figure 1). These measures feature an ornamented triplet line that is played by the piano in the original trio. In the four-hand version arranged by Czerny, the line is split between the two players. For a successful performance of the duet, the line must be seamlessly transferred from one player to the other as if they are one.

With transcriptions of large ensemble works, such as a symphony, the players become a far more powerful 'four-handed monster'; one that controls an entire symphony of sound. This challenges Brett's (1997) characterisation of fourhand arrangements, namely that they "tame the concert-hall repertory of symphonies and chamber music for the drawing room" (p. 153). Arrangements were not designed to tame the concert repertoire. Instead, they were designed to transport the grandeur of the symphony into the home environment. Evidence of this can be gleaned from the scores themselves. Arrangers often go to great lengths to squeeze as much sound out of the piano as possible. Figure 2, for example, shows the opening measures of a four-hand arrangement of Wagner's Der fliegende Holländer. In measures 13-14 and 17-18, the arranger, Louis Oesterle, has added crescendos to encourage the players to play as loudly as possible. These crescendos are not found in the orchestral score. 

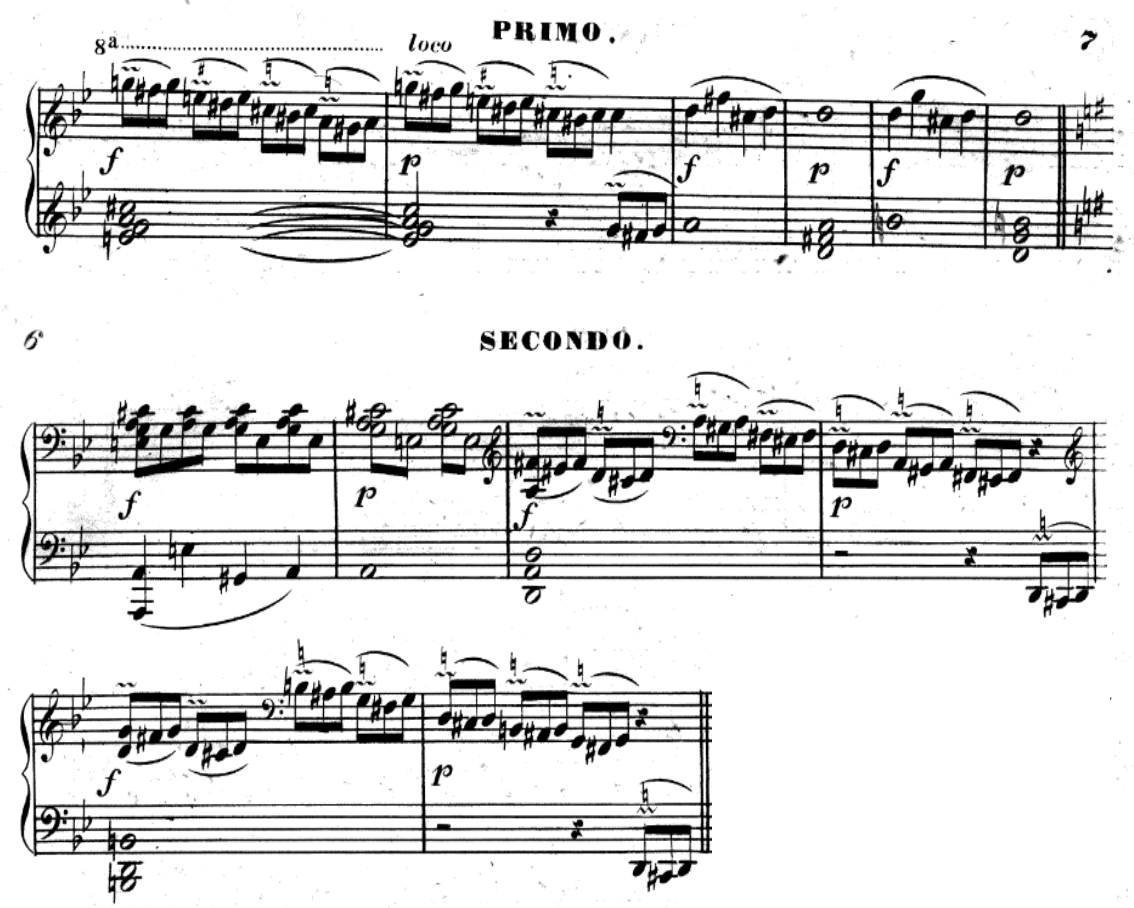

Figure 1. Beethoven, 'Archduke' trio Op. 97, first movement mm. 32-41. Four-hand arrangement by Carl Czerny, (Vienna: Tobias Haslinger, c. 1838).
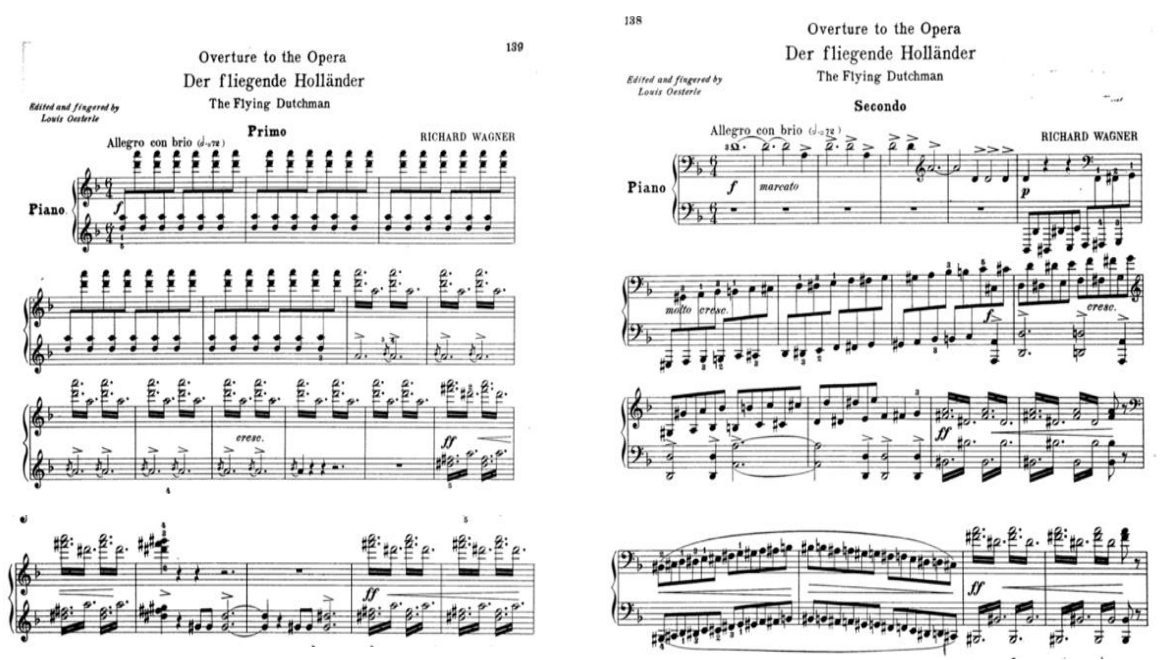

Figure 2. Overture to Wagner's Der fliegende Holländer. Four-hand arrangement by Louis Oesterle (1909). 


\section{Hands-On Experience}

Arrangements helped to facilitate a deeper understand of serious music. The British composer William Crotch noted in 1818 , that 'the advancement of musical taste' was largely due to "the more general performance on the piano forte of musical originally intended for an orchestra" (Crotch, 1818/1999, p. 215).

Unlike at a concert, amateurs at home were in control of the music. In the passage below, a writer for the Leipzig Allgemeine musikalische Zeitung (1865) discussed how repeated readings of the same score could help amateurs better understand complex, serious music-in this case, Beethoven's symphonies, overtures, and string quartets. This 'domestic music contemplation,' as the author called it, was likely a major factor in the acceptance and understanding of serious repertoire in the nineteenth-century,

What help is it for the familiarity of such profound works if at most one can hear each of these works performed once a year (a chance only those lucky enough to live in Vienna have)? The music is performed, and, understood or not, time passes inexorably by. Another piece follows or the concert ends, and the performers pack up their instruments. How different it is on the piano during domestic musical contemplation. One repeats a piece that is not immediately clear two or three times, perhaps picking it up again in a few days, until it has become transformed to flesh and blood, and one knows thoroughly every succession and each individual detail. After such study (which is not uncommon even among amateurs) one can soon form a completely different judgment concerning the most difficult of Beethoven's 'last' quartets. (cited in Christensen, 1999, p. 263)

Playing four-hand transcriptions and attending concerts were mutually reinforcing activities. Concerts provided the impetus for amateurs to buy and play transcriptions and, since playing is a far deeper form of musical engagement than listening, transcriptions enriched the public's appreciation and understanding of serious music, thus increasing their appetite for such works in the concert hall. Evidence of this reciprocal relationship can be seen in the title pages of many symphonic transcriptions. Figure 3, for example, shows the title page of a four-hand transcription of Haydn's 'Surprise' Symphony Hob. I:94 published around 1800. The title makes reference to Salomon's famous concert series at which the symphony was premiered. Similarly, the title page of a four-hand transcription of Haydn's symphony in B-flat major, Hob. I:108 published in 1815 includes the subtitle "As Performed at the Philharmonic Society" (see figure 4).

Figure 5 shows an advertisement from The Musical World (1838) for recently published music by Beethoven-the paragon of serious music. Arrangements and piano works are listed side by side. Notably, the first and last items listed are both arrangements of the nine symphonies.

Judging by the total number of editions published, arrangements of Beethoven's symphonies eclipsed his piano sonatas in terms of their popularity in the opening decades of the nineteenth-century (Hirsch and Oldman, 1953). Elsewhere I have argued that Beethoven's piano sonatas became popular with amateur musicians only after they were performed on public concerts (Miller-Kay, 
2016). The greater popularity of symphony arrangements in the first half of the nineteenth century is thus evidence of a link between public performance and domestic music-making.

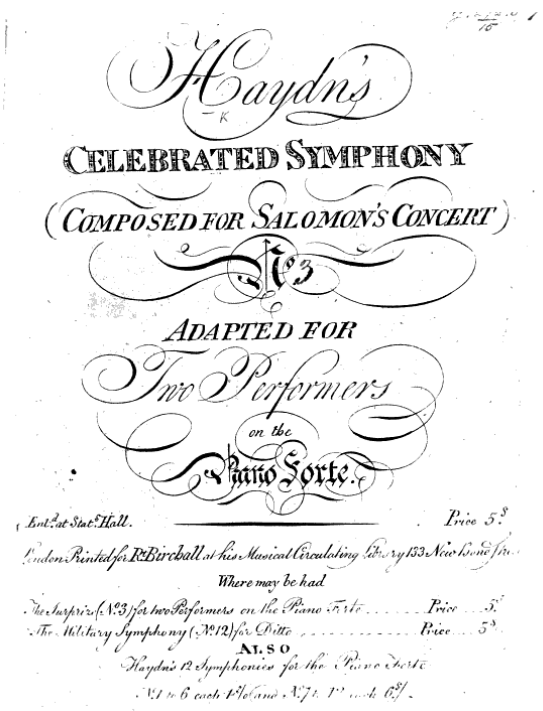

Figure 3. Title page of Haydn 'Surprise' Symphony, likely arranged by W. Watts and published by Birchall and Co. (c. 1800).

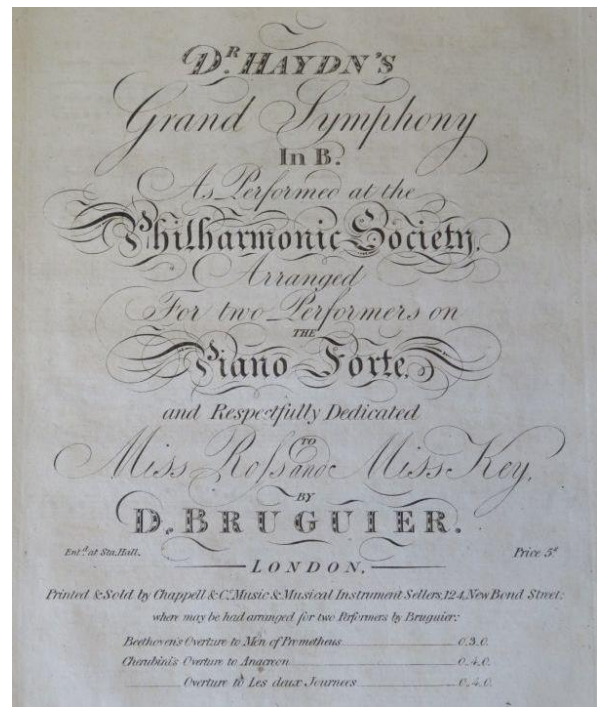

Figure 4. Title page of Haydn Symphony symphony in B-flat major, Hob. I:108, arranged by D. Bruguier and published by Chappell and Co. (c. 1815). 


\section{TO PIANOFORTE PLAYERS.} Just Published, Beethoven's nine grand symphonies newly arranged for the piano by Kalkbrenner. each 6s. and 8s. 6d. Bcethoven's six grand sonatas (masterpieces), edited by Czerny, viz -his sonatas, Op. 13, 26, 28, 27, 57, and 80, each 4s, $;$ and ditto's six airs, with variations, each $2 s$. $6 \mathrm{~d}$.; and as duets, arranged by Czerny, Beethoven's nine symphonies, each 8 , and 10s. 6d.; and his septet, 10s. 6d. Ca: talogues gratis.

Figure 5. Advertisement in The Musical World (1838).

Four-hand arrangements played important roles in the lives of professional musicians as well. In conversation with Robert Craft, Stravinsky (1960) recalls the following from his lessons with Leokadiya Kashperova, which he began in 1899, "she tried to discourage my interest in Wagner. Nevertheless, I knew all Wagner's works from the piano scores...we played Rimsky's operas together, four-hands, and I remember deriving much pleasure from Christmas Eve this way" (p. 25).

And, Isabelle Vengerova (1929), a prominent American pianist and pedagogue, reminisced on the important role that four-hand arrangements played in her early musical education,

...the piano was the first medium through which music was revealed to me. I was not quite five years old when I listened to the playing of my elder sisters, who almost every evening used to play 'four hands.' It was Mozart's Symphony in G minor which led me over to my dreams. Impressions of childhood often stay with us for life, and so this symphony remains fixed in my memory as the most beautiful and touching music. (p. 114)

Many composers mention four-hand playing in reference to friendships with each other. For example, Saint-Saëns relays the following story regarding his friendship with Anton Rubinstein (cited in Huneker, 1911),

I acquired his friendship in deciphering upon his own piano the orchestral score of his Ocean Symphony. I read very well then, and his symphonic music, written large and black, was not very difficult to read.

From this day a lively sympathy united us; the simplicity and evident sincerity of my admiration touched him. We were together assiduously, often played together for four hands, subjected to rude tests the piano which served as our field of battle, without regard to the ears of our hearers. It was a good time! We made music with passion simply for the sake of making it, and we never had enough. I was so happy to have encountered an artist who was wholly an artist, exempt from the littleness which sometimes makes so bad a barrier around great talent. (pp. 387-88) 
Similarly, Nikolay Kaschkin, a music critic and piano professor, spoke of playing four-hand repertoire with Tchaikovsky as an after dinner entertainment,

Left to ourselves we immediately went to the piano...and began to play arrangements for four hands, of which Tchaikovsky had a large store. We often played Brahms, whom he esteemed very highly for his seriousness and sincerity, and his contempt for superficial success; but at the same time he had not much sympathy with his music, finding it cold and dry. (Newmarch, 1900, p. 95)

Four-hand playing served many of the same purposes for professionals as for amateurs. It was a social activity - a meaningful way of engaging with other musicians in friendship. It was also, of course, educative. To judge from various memoirs and journals, many prominent nineteenth-century composers came to know the music of their predecessors and contemporaries principally by playing arrangements. Some composers would also arrange music for the piano at sight, as Saint-Saëns relays in the above quote.

Many nineteenth-century composers also worked as arrangers. Wagner claimed that he learned a great deal as a young composer from transcribing Beethoven's ninth symphony for the piano, and Brahms worked as an arranger in his youth under the pseudonym, 'G. W. Marks' (Christensen, 1999). Later in life, Brahms arranged many of his own works for the piano. Sometimes, however, his attitude towards arrangement would turn sour. When sending a four-hand arrangement of his piano concerto to his publisher, he instructed that his name be left off the title page,

do not mention my name as the arranger! After all, it is just a lot of scribbling, and it does not look right if the Master himself creates out of his own work as ungainly a monstrosity as a 4-hand concerto is bound to be! (Avins, 1997, p. 288)

\section{The Value of Inauthenticity}

How is a work transformed when it is arranged for piano? In the preface to his solo piano arrangements of Beethoven's symphonies, Liszt explains the transformation with two analogies,

I will be satisfied if I stand on the level of the intelligent engraver, or the conscientious translator, who grasps the spirit of a work and thus contributes to our insight into the great masters and to our sense of the beautiful. (Liszt, $1865 / 1998$, preface, italics added)

The analogies of the engraver and translator are both apt. Transcription can be like translation: adapting music from the language of the orchestra to that of the piano. Like any expert translator, a good arranger must be fluent in both languages. At the same time, a piano arrangement will always contain less colour than its orchestral original; there are simply fewer colours to play with. In this sense, the art of transcribing is very much like that of engraving: reducing a colourful painting to a black-and-white copy. The more expertly crafted a transcription is, the more like a 
translation it is. The less thoughtfully produced it is, the more it has in common with an etching. Etchings, incidentally, just like this second class of transcriptions, were mass produced.

However, the etching-like lack of colour in transcriptions has its benefits. E. T. A. Hoffmann (1810) hints at this in his famous review of Beethoven's fifth symphony, "The piano reproduces the great work as a sketch reproduces a great painting, and the imagination brings it to life with the colours of the original" (Charlton, 1989, p. 251). The role of the imagination is a key. Playing transcriptions requires the players to not only exercise their technical and musical abilities, but their musical memories and powers of imagination. "Attending a concert after such private study," wrote a reviewer for the Leipzig Allgemeine musikalische Zeitung (1842), "one's ear will be struck by the fresh colours of the instruments...an advantage that is not to be dismissed lightly" (Christensen, 1999, p. 263).

The fact that four-hand arrangement played by amateurs would pale in comparison to the sound of a live symphonic performance was an advantage, not a disadvantage in that it made the live event that much more magnificent. In this way, four-hand transcriptions are at the opposite end of the spectrum from the high fidelity recordings of today. With modern recording equipment and post-production editing software, today's recordings can sound cleaner and more vividly coloured than live performances.

In the twentieth century, not only did four-hand arrangements become unnecessary, they also became aesthetically objectionable. Performers and critics increasingly valued what was authentic; what was true to the composer's intensions. For example, in a survey of English editions of Beethoven's music made in the composer's day, Hirsch and Oldman (1953) noted that many of the composer's more popular works 'had to submit' to the 'indignity' of arrangement (p. 2). These comments reveal a great deal about how arrangements were viewed in the 1950s. Hirsch and Oldman's statement would most certainly have struck nineteenth-century amateurs as strange.

\section{Pedagogical Applications}

This study provides strong evidence for the important role that active engagement plays in music appreciation. In nineteenth-century Europe, four-hand piano transcriptions served important social and educative functions, and were enthusiastically embraced by amateurs and professional musicians alike. The enjoyment of listening to symphonic repertoire in the concert hall and playing it at home mutually reinforced one another.

The rise of recordings in the early twentieth century and the concomitant demise of transcriptions has made contemporary classical music culture far more passive. While a wholesale revival of four-hand transcription playing would be neither be desirable nor possible, the practice can serve as a useful model and source of inspiration to those who wish to encourage more active engagement with symphonic repertoire today.

There are several ways the culture of four-hand playing can be adapted to suit our modern world. Firstly, music teachers would find advantage in reviving the 
link between at-home playing and concert attendances. Prior to or after a concert, students of any instrument would benefit from reading through arrangements or excerpts from the repertoire performed. The history of arrangements demonstrates the important role that this kind of active engagement plays in musical understanding and appreciation.

Ensemble playing and sight-reading activities can be integrated into college level music study in both areas of music theory and music history. In music history in particular, it is common for students to be given listening assignments. These could be replaced by playing assignments. Students could prepare easy and/or short arrangements from the repertoire to be discussed and play these for each other in class. Following these in-class performances, recordings could be played, bringing to light the added colour of the original version.

Along similar lines, pre-concert talks for lay audiences could be made more helpful and enjoyable through the inclusion of interactive activities. Such activities could be as simple as singing the main themes from an upcoming symphony in a call and response manner. This would help familiarise audience members with the musical themes they were about to hear and would also add an interactive, social dimension to the concert. More effective, although more logistically challenging, would be pre-concert reading parties wherein a few members of the orchestra would meet with interested parties to read through selections from an upcoming concert together. These readings could be organised flexibly, to accommodate any and all instruments. The unpredictable sound of the ensemble at each party would only add to the fun. Such events would not be performances; the goal would not be to faithfully reproduce the music as the composer intended. Instead, the purpose would be to share the joy of music-making. These parties would be similar in ethos to that of Saint-Saëns' and Rubenstein's four-hand playing as described by Saint-Saëns above.

Studying the musical and social functions of arrangements in the nineteenth century brings the changes that have manifest in the last hundred years or so into sharp relief. As recordings are replaced by the internet, the culture of classical music is once again undergoing a tectonic shift. Awareness of the nineteenth-century musical practices discussed herein can help performers, educators and music scholars move towards a more varied and engaged future for classical music performance and appreciation.

\section{References}

Avins, S. (Ed.). (1997). Johannes Brahms: Life and letters. Oxford, UK: Oxford University Press.

Botstein, L. (2009). Time and memory: Concert life, science, and music in Brahms's Vienna. In W. Frisch (Ed.), Brahms and his world (pp. 3-29). Princeton, NJ: Princeton University Press.

Brett, P. (1997) Piano four-hands: Schubert and the performance of gay male desire. Nineteenth-century music 21(2), 149-176. doi:10.2307/746896

Charlton, D. (ed.). (1989). E. T. A. Hoffmann's music writings: Kreisleriana, the poet and the composer, music criticism (Martyn Clarke, Trans.). Cambridge, NY: Cambridge 
University Press.

Christensen, T. (1999). Four-hand piano transcription and geographies of nineteenth-century musical reception. Journal of the American Musicological Society, 52(2), 255-298. doi:10.2307/831999

Cone, E. (1974). The composer's voice. Berkeley, CA: University of California Press. Crotch, W. (1999). Introductory lecture. In H. L. Irving (Ed.), Ancients and moderns: William Crotch and the development of classical music, (pp. 212-18). Aldershot, UK: Ashgate.

Ehrlich, C. (1990). The piano: A history (revised ed). Oxford, UK: Clarendon Press.

Grove, G. (1962). Beethoven and his nine symphonies (3rd. ed.). New York, NY: Dover.

Hirsch, P. \& Oldman, C. B. (1953). Contemporary English editions of Beethoven. Music review, 14, 1-35.

Hofmeister, A. M. (1845). Handbuch der musikalischen literatur (3rd ed., Vol. 2). Leipzig, Germany: Friedrich Hofmeister. Retrieved from https://imslp.org/wiki/ Special:ReverseLookup/101201

Hullah, J. (1877). Music in the house (2nd ed.). London, UK: Macmillan and Co. Retrieved from https://archive.org/details/musicinhouse00hullgoog

Huneker, J. (1911). Franz Liszt. New York, NY: Charles Scribner's Sons. Retrieved from https://archive.org/details/franzliszt00huneuoft

Liszt, F. (arr.). (1998). Beethoven symphonies nos. 1-5 transcribed for solo piano (A. Walker, trans.). Mineola, New York, NY: Dover (Original work published 1865)

Miller-Kay, E. (2016). The virtuosity of interpretation: The performance history of Beethoven's piano sonatas in London, 1800-1880 (Doctoral Thesis). New York University, New York.

Newmarch, R. (1900). Tchaikovsky: His life and works. New York, NY: The Bodley Head. Retrieved from https://archive.org/details/tchaikovsky008090mbp

Oesterle, L. (arr.). (1909). Overture to Wagner's Der fliegende Holländer. New York, NY: Schirmer. Retrieved from https://imslp.org/wiki/Special:ReverseLookup/ 155318

Rowland, D. (1993). A history of pianoforte pedalling. Cambridge, NY: Cambridge University Press.

Stravinsky, I. and Craft, R. (1960). Memories and commentaries. Garden City, New York, NY: Doubleday and Co. Retrieved from https://archive.org/details/memories commenta1960stra

Taylor, I. (2010). Music in London and the myth of decline. Cambridge: Cambridge University Press.

Temperley, N. (1959). Instrumental music in England, 1800-1850 (doctoral thesis). doi: 10.17863/CAM.15935

Van Camp, L., \& Ottley, J. (2002). A practical guide for performing, teaching, and singing the Brahms "Requiem." Los Angeles, CA: Lawson-Gould Music Publishers.

Vengerova, I. (1929). The piano as it seems to me. In Overtones: The monthly publication of the Curtis Institute of Music 1(5), 114-116. Retrieved from https://archive.org/ details/overtones1930curt

\section{Biography}

Dr. Elissa Miller-Kay is a lecturer in Piano Performance and Musicology at the Princess Galyani Vadhana Institute of Music in Bangkok, Thailand. Her principal research interests are Beethoven reception, nineteenth-century performance practices, and piano pedagogy. Dr. Miller-Kay holds degrees in Piano Performance from Oberlin College (Bachelor of Music), 
Mannes College (Master of Music), and New York University (Doctor of Philosophy). Her dissertation examined the reception and performance history of Beethoven's piano sonatas in London, 1800-1880. Dr. Miller-Kay also holds a Licentiate Diploma in Piano Performance (First Class Honours) from the Royal Conservatory of Music in Toronto, Canada. Performance awards include first prize at the International Beethoven Piano Sonata Competition in Memphis, TN (2009) and the Ben Steinberg Musical Legacy Award (2006). 